Official Publication of the Indian Pharmacological Society

October 2007 Vol $39 \quad$ Issue 5

\section{Indexed / Listed in}

Science Citation Index, Journal Citation Report, Biological Abstracts/Biosis, Chemical Abstracts, EMBASE/Excerpta Medica, CAB Abstract, Global Health, Excerpta Medicinal and Aromatic Plants Abstracts, Health \& Wellness Research Center, Health Reference Center Academic, InfoTrac One File, Expanded Academic ASAP, NCI Current Contents, Indian Science Abstracts, IndMed, and Medind.

\section{Publication}

The journal is published six times in a year in the months of February, April, June, August, October and December.

\section{Copyright and Photo-copying}

No part of this publication may be reproduced or transmitted in any form or by any means, electronic or mechanical, including photocopy without permission in writing from the Chief Editor.

\section{Correspondence}

Enquiries should be addressed to the Chief Editor.

\section{Disclaimer}

The Chief Editor disclaims any responsibility for statements made and opinions expressed by authors or claims made by the advertisers.

\section{Disputes}

Readers, contributors, members and advertisers may approach the President, IPS, in case of disputes with the IJP.

The journal is printed on acid free paper

\section{IPS Members}

The issues are supplied for Rs. 5.00 to members in India. Members residing overseas can get the issues on payment of US\$ 25/ annum towards airmail charges.

\section{Missing Issues}

Claims for missing issues should be sent within 2 months of issue date.

\section{Published by}

Medknow Publications

A-109, Kanara Business Centre, Off Link Road, Ghatkopar (E), Mumbai - 400075,

India. Phone: 91-22-6649 1818/1816,

Fax: 91-22-6649 1817,

Web: www.medknow.com

\section{Websites}

www.ijp-online.com

www.journalonweb.com/ijp

www.bioline.org.br/ph

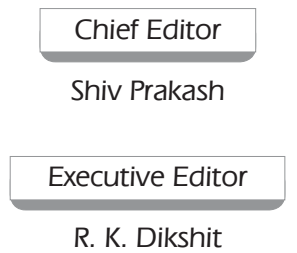

\begin{tabular}{|c|}
\hline Associate Editor \\
Varsha Patel
\end{tabular}

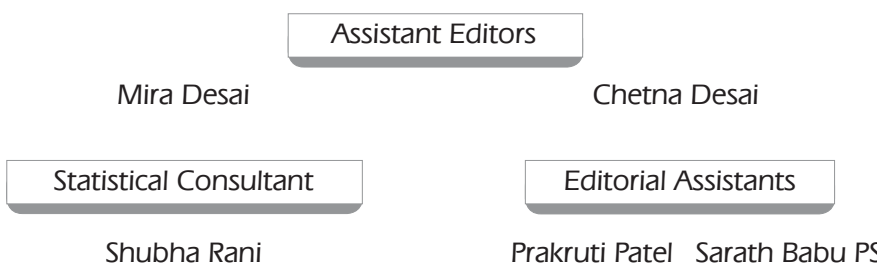

\begin{tabular}{ll}
\cline { 2 - 2 } & \multicolumn{1}{c}{ International Advisory Board } \\
\cline { 2 - 2 } Adithan C, India & Anil Gulati, USA \\
Bhaskar Jasti, USA & Diwan PV, India \\
Ding Jian, China & Gupta JB, India \\
Gambhir SS, India & Gupta YK, India \\
Jagadish G, USA & Lennard MS, UK \\
Manjeet Singh, India & Mario A. Gonzalez, USA \\
Mehendale HM, USA & Naidu MUR, India \\
Nanivadekar AS, India & Narayana DBA, India \\
Ozturk Y, Turkey & Pipasha Biswas, UK \\
Rao V.S.V. Vadlamudi, India & Uthai Suvanakoot, Thailand
\end{tabular}

Editorial Board

Arunabha Ray, Delhi

Dinesh Kumar, Hyderabad

Jagadeesh K, Davangere

Kulkarni SK, Chandigarh

Malik JK, Izatnagar

Mody SK, Sardar Krushinagar

Moulik SK, Delhi

Pundarikakshadu K, Ahmedabad

Rama Rao P, Chandigarh

Ramesh K. Goyal, Ahmedabad

Seshagiri Rao C, Hyderabad

Sushma Mengi, Mumbai

Thatte UM, Mumbai

G. Parthasarathy, Mysore
Bhupendra Singh Bhoop, Chandigarh

Flora SJS, Gwalior

Katiyar CK, Delhi

Madhu Dikshit, Lucknow

Mallikarjuna Rao C, Manipal

Mohanasudaram J, Chennai

Nilima Kshirsagar, Mumbai

Rajan Vedasiromani J, Kolkata

Ramkishan A, Ahmedabad

Roy BK, Ranchi

Shankarnarayana A, Coimbatore

Tripathi SK, Kolkata

Usharani P, Hyderabad

RS Bhatia, Ludhiana 


\section{Indian Journal of Pharmacology}

Official Publication of the Indian Pharmacological Society

October 2007 Vol 39 Issue 5

\section{CONTENTS}

\section{Editorial}

Irrational combinations: No consideration for patient safety: Shiv Prakash

\section{Review Article}

Bioequivalence: Issues and perspectives: Shubha Rani

\section{Research Papers}

Isolation, characterization and study of enhancing effects on nasal absorption of insulin in rat of the total saponin from Acanthophyllum squarrosum: S.A. Sajadi Tabassi, H. Hosseinzadeh, M. Ramezani, E. Moghimipour, S.A. Mohajeri

Pharmacological and biochemical evidence for the antidepressant effect of the herbal preparation Trans-01: Md. Shalam, S.M. Shantakumar, M. Laxmi Narasu

Effects of dexamethasone and betamethasone as COX-2 gene expression inhibitors on rigidity in a rat model of Parkinson's disease: Mehdi Shafiee Ardestani, Hassan Mehrab, Nourallah Sadeghzadeh

Activity of aqueous ethanol extract of Euphorbia prostrata ait on Shigella dysenteriae type 1-induced diarrhea in rats:

Kamgang René, Gonsu Kamga Hortense, Wafo Pascal, Mbungni N. Jean Alexis, Pouokam Ervice Vidal,

Fokam Tagne Michel Archange, Fonkoua Marie Christine

Antidiarrheal and antimicrobial activities of Stachytarpheta jamaicensis leaves: S. Sasidharan, L. Yoga Latha, Z. Zuraini, S. Suryani, S. Sangetha, L. Shirley

\section{Research Letters}

Positive inotropic and chronotropic effect of aloe gel on isolated rat heart: Pradeep Kumar, Manish Goyal, Sunita Tewari

Synergistic effect of cefixime and cloxacillin combination against common bacterial pathogens causing community acquired pneumonia: Astha Agarwal, N. Jain, A. Jain

In vitro cytotoxic and human recombinant caspase inhibitory effect of Annona reticulata leaves: Susanta Kumar Mondal, Nirup Bikash Mondal, Upal Kanti Mazumder

\section{Correspondence}

Counterfeit and substandard drugs: The need for an effective and stringent regulatory control in India and other developing countries: A. Sukhlecha

\section{Letter to the Editor}

Postgraduate education in medical pharmacology: A student's viewpoint: Varun Gupta

\footnotetext{
The copies of the journal to members of the association are sent by ordinary post. The editorial board, association or publisher will not be responsible for non-receipt of copies. If any of the members wish to receive the copies by registered post or courier, kindly contact the journal's / publisher's office. If a copy returns due to incomplete, incorrect or changed address of a member on two consecutive occasions, the names of such members will be deleted from the mailing list of the journal. Providing complete, correct and up-to-date address is the responsibility of the members. Copies are sent to subscribers and members directly from the publisher's address; it is illegal to acquire copies from any other source. If a copy is received for personal use as a member of the association/society, one cannot resale or give-away the copy for commercial or library use.
} 


\title{
Effects of dexamethasone and betamethasone as COX-2 gene expression inhibitors on rigidity in a rat model of Parkinson's disease
}

\author{
Mehdi Shafiee Ardestani, Hassan Mehrab르, Nourallah Sadeghzadeh
}

\section{Department of Medicinal Chemistry and Radiopharmacy, Faculty of Pharmacy, Tehran University of Medical Sciences, Tehran, ${ }^{1}$ Department of Biotechnology, Faculty of Pharmacy, Mashhad University of Medical Sciences, Mashhad, Iran}

Received: 11.05.2007

Revised: 10.08 .2007

Accepted: 12.10 .2007

Correspondence to:

Mehdi Shafiee Ardestani

E-mail: shafieeardestani@gmail.com

\begin{abstract}
Parkinson's disease (PD) is a neurodegenerative disease in the nigrostriatal pathway of animals and humans and is responsible for most of the movement disorders, including the rigidity. Increasing evidence suggests that an inflammatory reaction accompanies the pathological processes caused by cyclooxygenase-2 (COX-2) seen in many neurodegenerative disorders, including PD. In this study oral betamethasone and dexamethasone were administrated to parkinsonian rats chronically and their effect on rigidity was evaluated. As the results of this study show, both the molecules were able to decrease rigidity.
\end{abstract}

KEY WO RDS: Betamethasone, dexamethasone, inflammation, Parkinson's disease
Cyclooxygenase (COX) is the first enzyme in the prostaglandinprostacyclin-thromboxane pathway. It converts arachidonic acid to prostaglandins and thromboxanes, which are collectively known as its metabolites. ${ }^{[1]}$ Three COX isoforms-COX-1, COX-2 and COX3 -have been identified. COX-1 is the constitutive form of COX and performs a housekeeping function to synthesize prostaglandins, which are involved in regulating normal cellular activities. In contrast, COX-2 is the inducible form of COX, as its expression can be induced by inflammatory stimuli or mutagens, tumor necrosis factor-alpha (TNF- $a$ ) and the transcription factor CCAAT enhancer binding protein (c/EBP) beta. The brain possesses both COX-1 and COX-2 isoforms. There is COX-2 upregulation during stressful conditions such as cerebral ischemia; it is also upregulated by neuronal apoptosis and neurobehavioral defects. ${ }^{[2]}$

In addition, steroidal anti-inflammatory drugs such as dexamethasone can inhibit COX-2 gene expression. The glucocorticoids have widespread effects because they influence the function of most cells in the body. Glucocorticoids dramatically reduce the manifestations of inflammation. This is due to their profound effects on the concentration, distribution and function of peripheral leukocytes and their suppressive effects on the inflammatory cytokines, such as TNF-a or interleukin-6 (IL-6) and chemokines or other lipid and glucolipid mediators of inflammation. In addition to these effects, glucocorticoids influence the inflammatory response by reducing the prostaglandin synthesis that results from activation of phospholipase $\mathrm{A}_{2} \cdot{ }^{\left[{ }^{[3]}\right.}$
COX-2 appears to be expressed in dendrites and cell bodies of neurons in several areas of the brain, including the nigrostriatal pathway, CA-1 hippocampus and amygdala nucleus. ${ }^{[4]}$

Among the COX isoenzymes, only COX-2 corresponds to inflammatory and degenerative brain disease. ${ }^{[5]}$ Parkinson's disease (PD) is a degenerative neurodopaminergic disease in the nigrostriatal pathway of humans. The loss of nerve terminals, accompanied by dopamine deficiency, in this pathway are responsible for most of the movement disorders. ${ }^{[6]}$ Increasing evidence suggests that an inflammatory reaction accompanies the pathological processes seen in many neurodegenerative disorders, including PD. ${ }^{[7,8]}$ Glial activation is part of a defense mechanism to remove debris and pathogens and promote tissue repair. However, inflammatory activation of microglial cells may contribute to the neurodegenerative process through structural invasion and the release of proinflammatory cytokines, reactive oxygen species (ROS), nitric oxide (NO) and excitatory amino acids at synapses and cell bodies. ${ }^{[9]}$ In cell culture and animal models, inflammation contributes to neuronal damage and nonsteroidal anti-inflammatory drugs (NSAIDs) have been shown to provide some neuroprotection in different paradigms, ${ }^{[10]}$ including PD models. ${ }^{[11]}$ Reactive microglia inhibits neuronal cell respiration via NO and causes neuronal cell death in vitro and in vivo. ${ }^{[12]}$ Investigators have reported an uncertain relationship between COX-2 and its inhibition by NSAIDS and PD. They suggest that chronic use of 
NSAIDs can decrease the risk of PD. ${ }^{[13]}$ They also suggest that there is a role for COX-2 in degenerative diseases such as PD. ${ }^{[14]}$ In addition, there is the evidence that steroidal compounds like dexamethasone can protect dopaminergic neurons against the lesion. ${ }^{[15]}$ These studies have not examined the effect of COX-2 gene expression inhibitors, such as the steroidal antiinflammatory drugs dexamethasone and betamethasone, on the rigidity of $\mathrm{PD}$. In the present study, we have investigated the effect of the COX-2 gene expression inhibitors on the rigidity seen in PD.

\section{Materials and Methods}

\section{Animals}

Ninety male albino Wistar rats (200-250 gm) were the subjects in the present study. The animals were purchased from Pasteur Institute of Iran and then housed in groups of ten in stainless steel cages, handled daily and provided food and water ad libitum. A 12-h light/12-h dark cycle was maintained; the animals were tested during the light cycle. These animal experiments were carried out in accordance with recommendations of the declaration of Helsinki and the internationally accepted principles in the use of experimental animals. In this study, we divided the animals into nine groups as shown in Tables 1 and 2. Each group contained ten rats.

\section{Drugs and solvents}

Dexamethasone and betamethasone were purchased from Razak and Abidi Laboratories (Iran) and ketamine and xylazine were purchased from Merck (Germany). Dexamethasone was dissolved freely in glycerin 70\% and dimethyl sulfoxide (DMSO) $30 \%$ and betamethasone was dissolved freely in glycerin $70 \%$ and acetone $30 \%$; similarly, ketamine and xylazine were dissolved in distilled water.

\section{Surgery}

Each rat was anesthetized separately by intraperitoneal injection of $75 \mathrm{mg} / \mathrm{kg}$ of ketamine combined with $8 \mathrm{mg} / \mathrm{kg}$ xylazine. We prepared the rats for surgery and placed them in the stereotaxic instrument. The left substantia nigra pars compacta $(\mathrm{SNc})$ region of the nigrostriatum was targeted.

\section{Table 1}

\section{Description of the control and vehicle groups}

\begin{tabular}{lll}
\hline $\begin{array}{l}\text { Lesion of SNc } \\
\text { (Positive control) }\end{array}$ & $\boldsymbol{n}=\mathbf{1 0}$ & Received saline \\
\hline Negative control & $\mathrm{n}=10$ & Received saline \\
Sham & $\mathrm{n}=10$ & Received saline \\
Vehicle of dexamethasone & $\mathrm{n}=10$ & Received DMSO and glycerin \\
Vehicle of betamethasone & $\mathrm{n}=10$ & Received acetone and glycerin \\
\hline
\end{tabular}

\section{Table 2}

\section{Description of the test groups}

\begin{tabular}{ccl} 
Test group 1 & $n=10$ & Received dexamethasone $0.075 \mathrm{mg} / \mathrm{kg}$ \\
Test group 2 & $n=10$ & Received dexamethasone $0.15 \mathrm{mg} / \mathrm{kg}$ \\
Test group 3 & $n=10$ & Received betamethasone $0.12 \mathrm{mg} / \mathrm{kg}$ \\
Test group 4 & $n=10$ & Received betamethasone $0.24 \mathrm{mg} / \mathrm{kg}$ \\
\hline
\end{tabular}

Stereotaxic coordinators for the left SNc region were set at $-4.8 \mathrm{~mm}$ posterior and $-1.6 \mathrm{~mm}$ lateral to bregma and $8.2 \mathrm{~mm}$ ventral to the surface of the skull, according to the atlas of Paxinos and Watson. ${ }^{[16]}$

Stainless steel electrode was then placed in the left SNc and it was destroyed by the electrical lesion maker (Siemens, Germany), using an electrical current (1 mA, $8 \mathrm{~s})$. A lateral lesion of the SNc in each rat caused PD and its associated disorders, such as rigidity, due to the decrease in the inhibitory dopaminergic effects on the caudate nucleus and putamen, which are the main rigidity-inducing neurotransmitter releasing areas in the striatum. ${ }^{|3|}$ Because of these changes in the brains of the lesioned rats, there was rigidity of the limbs on both sides. Following surgery, they were kept in individual cages for 7-10 days and allowed to recover.

Estimation of violence and duration of lesion was estimated empirically in vitro by determination of clot dimensions in electrocardiograph gel caused by the electrical lesion maker and, finally, with animal examination and histological studies (Illustration 1) the actual lesion conditions were obtained. [Figure 1A-D] shows the accuracy and the precision of the lesion.

\section{Experimental procedure}

After recovery from surgery (i.e., after 7-10 days) all animals received daily oral COX-2 gene expression inhibitors for four weeks-either dexamethasone $(0.075$ or $0.15 \mathrm{mg} / \mathrm{kg})$ or betamethasone $(0.12$ or $0.24 \mathrm{mg} / \mathrm{kg}$ ) - depending on the test group to which the animal had been assigned. The same procedure was repeated in the control or vehicle groups as shown in Table 1. Murprogo's Method ${ }^{[17]}$ was then used to measure the rigidity of the animals $12 \mathrm{~h}$ after the last oral administration of drug or vehicle; the measurements were made at the following time points: $0,20,40,60,90,120,180$ and $240 \mathrm{~min}$. Wood platforms with steps of 3 and $9 \mathrm{~cm}$ were used

Figure 1: Histological study about accuracy the lesion of SNc in comparison with control groups (negative control and sham) Image A: $\mathrm{SNc}$ without microscopic magnification in control and sham groups Image B: SNc with microscopic magnification (4X) in control and sham groups Image C: Destroyed SNc in Parkinsonian rats without microscopic magnification Image D: Destroyed SNc in Parkinsonian rats with microscopic magnipcation (4X). Note: Chronic treatment of Parkinsonian rats did not improve lesion of the left SNc
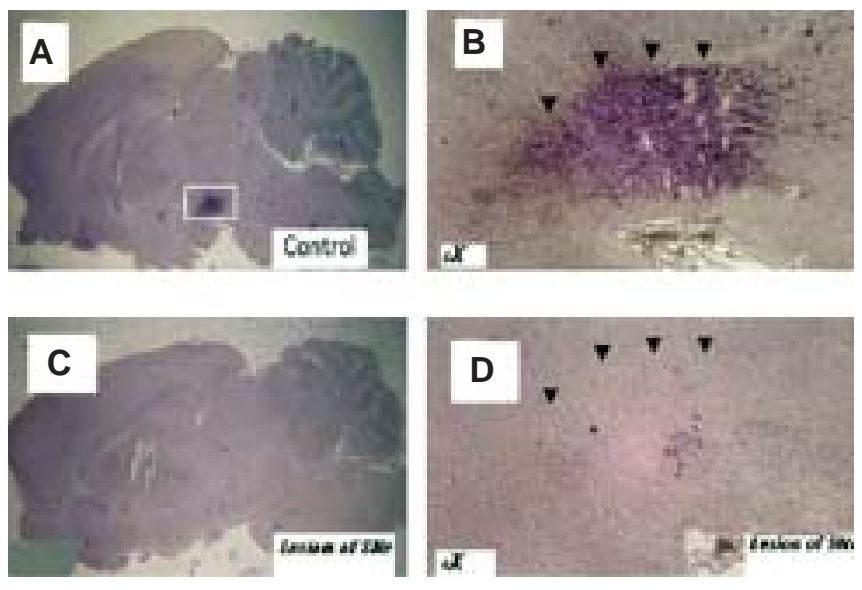
in this study. The procedure for the behavior experiments was as follows: At the beginning of the test, the animal was placed on the bench. If it did not move when touched, it received a score of 0.5. Next, the right paw of the animal was placed on the wood platform with the height of $3 \mathrm{~cm}$; if the animal did not take its paw off the platform after at least $10 \mathrm{~s}$, it received a score of 0.5 . The rigidity evaluation was repeated for the left paw and, as before, a score of 0.5 was given if the animal did not take its paw off the wooden platform after $10 \mathrm{~s}$. In the next stage of the procedure the right paw of the animal was placed on the $9 \mathrm{~cm}$ high wood platform, such that no other part of the animal touched the platform; the animal was given a score of 1 if it did not take its paw off the platform after $10 \mathrm{~s}$. This same procedure was repeated for the left paw.

It should be pointed out that when an animal had full rigidity (PD) it was given a total score of 3.5. Scores under 3.5 by Murprogo's Method indicate recovery from rigidity and the effectiveness of the treatment. After the Murprogo's test, each animal was decapitated and the brain was removed and kept in a $10 \%$ formalin solution. Randomly selected brains were cut on a cryostat; $50 \mu \mathrm{m}$ thick coronal sections were obtained, mounted on glass slides and stained with $\mathrm{H} \&$ E. Sections were examined under a light microscope to find out the accuracy of lesion of the left SNc. If the lesion was shown not to be in the SNc, any collected data on that particular animal were discarded.

\section{Results}

\section{Statistical analysis}

Nonparametric Kruskal-Wallis test, Wilcoxon test and one way analysis of variance (ANOVA) was used to compare the differences between groups; differences with $P$ values $<0.05$ were considered significant.

\section{Effect of betamethasone on rigidity in parkinsonian rats}

In those test groups which received betamethasone 0.12 and $0.24 \mathrm{mg} / \mathrm{kg}$, the rigidity in the PD model decreased and showed significant differences $(P<0.01)$ from sham, vehicle and positive control at all of the test times. Also, the test group that received betamethasone $0.24 \mathrm{mg} / \mathrm{kg}$ showed significantly greater reduction in rigidity than that which received betamethasone $0.12 \mathrm{mg} / \mathrm{kg}(\mathrm{P}<0.01$ at $0 \mathrm{~min}$ and 90 min; $P<0.05$ at 20,60 and 240 min; and $P>0.05$ at the other time points) [Figure 2].

\section{Effect of dexamethasone on rigidity in parkinsonian rats}

Our results showed that dexamethasone $(0.075$ and $0.15 \mathrm{mg} / \mathrm{kg}$ ) was able to decrease rigidity in the PD model, with significant differences $(P<0.01)$ from sham, vehicle and positive control at all of the test times. We found that dexamethasone $0.15 \mathrm{mg} / \mathrm{kg}$ had significantly greater effect than dexamethasone $0.075 \mathrm{mg} / \mathrm{kg}$, with $P<0.01$ at 0,20 and $60 \mathrm{~min}$ and $P<0.05$ at the other time points [Figure 3].

\section{Comparison of the effect of the two COX-2 gene expression} inhibitors on rigidity in parkinsonian rats

The test group that received dexamethasone $(0.075 \mathrm{mg} / \mathrm{kg})$ showed more reduction in rigidity than that which received betamethasone $(0.24 \mathrm{mg} / \mathrm{kg})$; the difference was statistically significant, with $P<0.01$ at 0,20 and $40 \mathrm{~min}$ and $\mathrm{P}<0.05$ at
Figure 2: Comparison of the mean rigidity grade in the groups that received betamethasone with that in the sham, negative and positive control groups. $\left({ }^{*} P<0.05\right)$ and $\left({ }^{* *} P<0.01\right)$

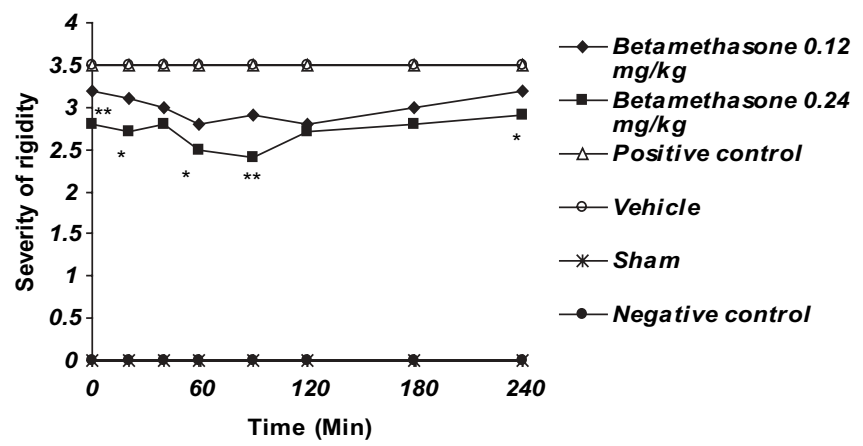

Figure 3: Comparison of the mean rigidity grade in the groups that received dexamethasone with that in the sham, negative and positive control groups. $\left({ }^{*} P<0.05\right)$ and $\left({ }^{* *} P<0.01\right)$

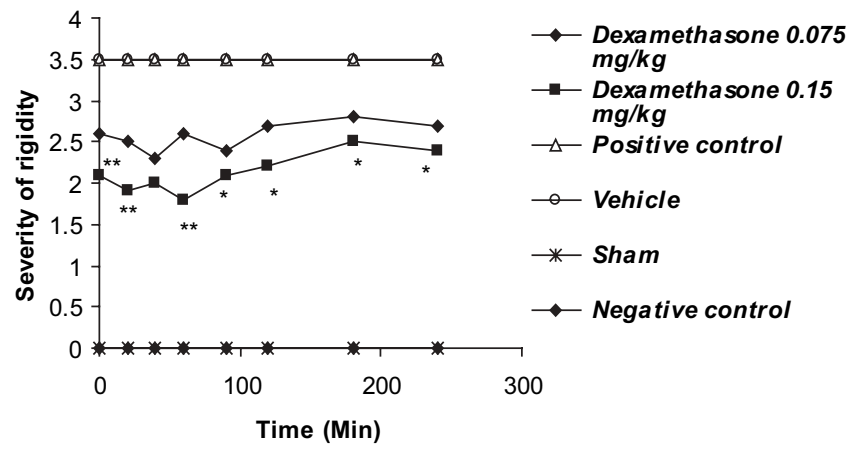

$240 \mathrm{~min}$. At the other time points there was no difference between the two in their ability to decrease rigidity in the PD model.

The test group that received dexamethasone $0.075 \mathrm{mg} / \mathrm{kg}$ showed significantly greater decrease in rigidity than the test group that received betamethasone $0.12 \mathrm{mg} / \mathrm{kg}$, with $\mathrm{P}<0.01$ at $0,20,40,90$ and $240 \mathrm{~min}$ and $\mathrm{P}<0.05$ at 90 and $180 \mathrm{~min}$; at 120 min the two test groups showed the same degree of decrease in rigidity. In addition, the test group that received dexamethasone $0.15 \mathrm{mg} / \mathrm{kg}$ showed significantly $(P<0.01)$ greater decrease in rigidity than the group that received betamethasone $0.24 \mathrm{mg} / \mathrm{kg}$ at all the evaluation time points; at 90 and 180 min the difference was statistically significant, with $P<0.05$.

Finally, we saw significant differences between the groups that received dexamethasone $0.15 \mathrm{mg} / \mathrm{kg}$ and that which received betamethasone $0.12 \mathrm{mg} / \mathrm{kg}$, with $\mathrm{P}<0.001$ for the differences at 0, 20, 40 and 60 min and $P<0.01$ at the other time points.

\section{Discussion}

Our observations show that the chronic use of COX-2 gene expression inhibitors, such as steroidal anti-inflammatory agents, caused an improvement in the rigidity of PD in the animal (rat) model. 
Reduction in rigidity in Parkinsonian rats was more with dexamethasone than with betamethasone and both the drugs were effective in reducing rigidity at all the evaluation time points during the study. Our findings also suggest that there is an important role for COX-2 gene expression in the management of the rigidity of PD. In agreement with our work, a previous study, ${ }^{[18]}$ using postmortem analysis, has shown that COX-2 and prostaglandin $\mathrm{E}_{2}$ level are increased in the brains of persons who suffer from PD.

In another study, Riechman and Hokin ${ }^{[19]}$ suggested that COX-2 causes an increase in the level of acetylcholine in the brain through the production of prostaglandin $\mathrm{E}_{2}$ and by an increase in the expression of cholinergic markers, such as choline acetyltransferase and vesicular acetylcholine transporter protein.

It is worth mentioning that prostaglandins, especially prostaglandin E2, have modulatory effects on adrenergic, noradrenergic and glutaminergic transmission and prostaglandin synthesis inhibitors increase the blood pressure by increasing catecholamine release; for example, using large doses of glucocorticoids in humans may cause insomnia, euphoria and increase in intracranial pressure. ${ }^{[3]}$ In addition, some investigations have shown that COX-2 inhibitors impaired spatial memory by reducing acetylcholine levels in the brain but COX-1 inhibitors do not have any effect on spatial memory in rats. ${ }^{\mid 20]}$ Free radicals and glutamate cause degeneration in SNc and inhibition of these agents by antioxidants or glutamate antagonists protects neurons from degeneration. ${ }^{[1]}$ Other anti-inflammatory effects of steroidal anti-inflammatory drugs possibly include decreasing the production of free radicals and interference with calcium-mediated intracellular events..$^{[3]}$ Neuronal COX-2 overexpression may kill neurons in a cellautonomous manner and lead to the pathogenesis of $\mathrm{PD} ;{ }^{[22]} \mathrm{In}$ support of this hypothesis is the fact that COX-2 cell-autonomous toxicity may arise from the formation of ROS generated during COX peroxidase catalysis of prostaglandin $\mathrm{G}_{2}$ conversion to prostaglandin $\mathrm{H}_{2}$. That COX-2 cell-autonomous toxicity may arise from the formation of reactive oxygen species generated during COX peroxidase catalysis of prostaglandin G2 conversion to prostaglandin $\mathrm{H} 2$ and also electrons donation to COX, cosubstrate such as dopamine oxidized to dopamine-quinone and thus neuronal death is happe. In PD, there is evidence of an increase in the oxidative and inflammatory nigral environment, which includes the presence of (COX)-immunoreactive activated microglial cells in the substantia nigra. Microglial cells can also produce and release pro-inflammatory cytokines, in particular TNF- $a$ and cytotoxic molecules, including ROS and NO. ${ }^{[23]}$ Although such responses are nonspecific to lesion type, after 6-hydroxydopamine intrastriatal infusion there is an acute increase in TNF-a in the striatum. ${ }^{[24]}$ In this study we suggest that one of the possible mechanisms for the reduction in rigidity by administration of dexamethasone and betamethasone may probably be a decrease in microglial activation or/and the level of TNF-a, components of the inflammation pathway and free radicals in the striatum region. This hypothesis needs to be further investigated in future studies.

In another report scientists have suggested that aspirin and ibuprofen, as nonselective COX-2 inhibitors, significantly attenuate the decreases in dopamine uptake caused by glutamate and thus protect neurons against glutamate excitotoxicity in vitro. ${ }^{[25]}$ These observations suggest that other possible mechanisms exist by which dexamethasone and betamethasone caused reduction in rigidity in the present study. Inhibition of the enzyme COX-2 with inhibition of synthesis of prostaglandin $\mathrm{E}_{2}$, reduction in the level of acetylcholine in the brain and, probably, increase in the release of dopamine from dopaminergic neurons in the brain protects dopaminergic neurons from glutamate toxicity similarly to NSAIDS. In support of this, COX-2 inhibition and interference with cellular calciummediated events may be effective in achieving neurotransmitter release and recovery from rigidity.

\section{Acknowledgments}

The authors would like to thank Dr. Amin Gravand and Dr. Mostafa Saffari for their kind collaboration in the preparation of this article.

\section{References}

1. Xie WL, Chipman GJ, Robertson DL, Erikson RL, Simmons DL. Expression of a mitogen-responsive gene encoding prostaglandin synthase is regulated by $\mathrm{mRNA}$ splicing. Proc Natl Acad Sci USA 1991;88:2692-6.

2. Dubois RN, Abramson SB, Crofford L, Cupta RA, Simon LS, Van De Putte LB, et al. Cyclooxygenase in biology and disease. FASEB J 1998;12:1063-73.

3. Katzung BG. Basic and clinical pharmacology. Appleton and Lange: New York; 2004. p. 298-311, 577, 643-6

4. Yamagata K, Andreasson KI, Kaufmann WE, Barnes CA, Worley PF. Expression of a mitogen-inducible cyclooxygenase in brain neurons: Regulation by synaptic activity and glucocorticoids. Neuron 1993;11:371-86.

5. Minghetti L. Cyclooxygenase-2 (COX-2) in inflammatory and degenerative brain disease. J Neuropathol Exp Neural 2004;63:901-10.

6. McGeer PL, McGeer EG. Innate immunity, local inflammation and degenerative disease. Sci Aging Kowledge Environ; 2002:re3.

7. Drachman DB, Rothstein JD. Inhibition of cyclooxygenase-2 protects motor neurons in an organotypic model of amyotrophic lateral sclerosis. Ann Neurol 2000;48:792-5.

8. McGeer PL, Schwab C, Parent A, Doudet D. Presence of reactive microglia in monkey substantia nigra years after 1-methyl-4-phenyl-1, 2, 3, 6-tetrahydropyridine administration. Ann Neurol 2003;54:599-604.

9. Bal-Price A, Brown GC. Inflammatory neurodegeneration mediated by nitric oxide from activated glia-inhibiting neuronal respiration, causing glutamate release and excitotoxicity. J Neurosci 2001;21:6480-91.

10. Wu DC, Jackson-Lewis V, Vila M, Tieu $Y$, Teismann $P$, Vadseth $C$, et al. Ischiropoulos $\mathrm{H}$, Przedborski S. Blockade of microglial activation is neuroprotective in the 1-methyl-4-phenyl-1, 2, 3, 6-tetrahydropyridine mouse model of Parkinson disease. J Neurosci 2002;22:1763-71.

11. Hirsch EC, Hunot S, Damier P, Faucheux B. Glial cells and inflammation Parkinson's disease: A role in neurodegeneration. Ann Neurol 1998;44: S115-20.

12. Gao HM, Jiang J, Wilson B, Zhang W, Hong JS, Liu B. Microglial activationmediated delayed and progressive degeneration of rat nigral dopaminergic neurons: Relevance to Parkinson's disease. J Neurochem 2002;81:1285-97.

13. Asanuma M, Miyazaki I, Tsuji T, Ogawa N. New aspects of neuroprotective effects of nonsteroidal anti-inflammatory drugs. Nihon Shinkei Seishin Yakurigaku Zasshi 2003;23:111-9.

14. Teismann P, Tieu K, Choi DK, Wu DC, Naini A, Hunot S, et al. Cyclooxygenase-2 is instrument in Parkinson's Disease neurodegeneration. Proc Natl Acad Sci USA 2003;100:5473-8.

15. Kurkowska-Jastrzebska I, Litwin T, Joniec I, Ciesielska A, Przybylkowski A, Czlonkowski $\mathrm{A}$, et al. Dexamethasone protects against dopaminergic neuron damage in a mouse model of Parkinson's disease. Int Immunopharmacol 2004:4:1307-18.

16. Paxinos $G$, Watson $C$. The rat brain in stereotaxic coordinates. Academic Press: San Diego; 1997.

17. Murprogo $\mathrm{C}$. Effect of antiparkinson drug on a phenothiazine induced catatonia reaction. Arch Int Pharma Co Dyn 1962;137:48-90.

18. Buccafusco JJ, Lapp CA, Aronstam RS, Hays AC. Role of prostanoids in the regulation of central cholinergic receptor sensivity. J Pharmacol Exp Ther 
1993;266:314-22.

19. Reichman $M$, Nen W, Hokin LE. Acetylcholine releases prostaglandins from brain slices incubated in vitro. J Neurochem 1987;49:1216-21.

20. Sharifzadeh M, Tavasoli M, Naghdi N, Ghanbari A, Amini M, Roghani A, et al. Post-training intrahippocampal infusion of nicotine prevents spatial memory retention deficits induced by the cyclo-oxygenase-2-specific inhibitor celecoxib in rats. J Neurochem 2005;95:1078-90.

21. Etminan M, Gill SS, Samii A. Intake of vitamin E, vitamin $C$ and carotenoids and the risk of Parkinson's disease: A meta-analysis. Lancet Neurol 2002;4:362-5.

22. King D, Playfer JR, Roberts NB. Concentrations of vitamins A, C and E in elderly patients with Parkinson's disease. Postgrad Med J 1992;68:634-7

23. Mladenovic A, Perovic M, Raicevic N, Kanazir S, Rakic, L, Ruzdijic S. 6-Hydroxydopamine increases the level of TNFalpha and bax mRNA in the striatum and induces apoptosis of dopaminergic neurons in hemiparkinsonian rats. Brain Res 2004;996:237-45

24. Sánchez-Pernaute R, Ferree A, Cooper O, Yu M, Brownell L, Isacson O. Selective COX-2 inhibition prevents progressive dopamine neuron degeneration in a rat model of Parkinson's disease. J Neuroinflammation 2004;1:6.

25. Casper D, Yaparpalvi U, Rempel N, Wener, P. Ibuprofen protects dopaminergic neurons against glutamate toxicity in vitro. Neurosci Lett 2000;289:201-4. 